\title{
Aplikasi Pelelangan Ikan Online (E-Lelang) Berbasis Mobile
}

\author{
Stenly Ibrahim Adam ${ }^{\mathrm{a} 1}$, Fini Keni Celsia ${ }^{\mathrm{a} 2}$, Nadila Triyanita Katuuk ${ }^{\mathrm{a} 3}$ \\ ${ }^{a}$ Departemen Sistem Informasi, Fakultas Ilmu Komputer Universitas Klabat \\ Minahasa Utara, Indonesia \\ ${ }^{1}$ stenly.adameunklab.ac.id \\ ${ }^{2}$ S21710137@student.unklab.ac.id \\ ${ }^{3}$ S21710163estudent.unklab.ac.id
}

\begin{abstract}
Abstrak
Pemasaran hasil tangkapan nelayan ikan di Indonesia biasanya dilakukan dengan cara melelang ikan di tempat pelelangan ikan yang berada di pelabuhan. Lelang adalah proses penjualan terbuka antara penjual dan penawar, yang menawarkan harga tertinggi pada setiap barang atau jasa. Pemasaran dengan lelang terbuka seperti ini dapat mengalami kecurangan, contohnya manipulasi harga dari pihak pelelangan ke nelayan. Pemasaran seperti itu dapat berpengaruh pada kualitas ikan yang menurun, sehingga harga jual menjadi rendah. Berdasarkan masalah tersebut maka dalam artikel ini dikembangkan sebuah aplikasi E-lelang hasil tangkapan nelayan ikan berbasis mobile, yang dapat membantu pemasaran ikan di daerah kecil. E-lelang merupakan proses lelang, yang dilakukan secara online atau tidak harus berada di tempat lelang berlangsung. Penelitian ini menggunakan metode pengembangan Agile Software Development. Pengembangan aplikasi ini menggunakan framework React Native, Firebase sebagai back-end, dan beberapa tools yang mendukung pengembangan aplikasi. Hasil dari penelitian ini adalah berupa aplikasi mobile yang dapat dipasang pada perangkat Smartphone. Aplikasi ini dapat membantu pemasaran ikan secara efisien, dan penawar dapat melakukan bid pada setiap lelang yang ingin diikuti.
\end{abstract}

Kata kunci: E-Lelang, Mobile Application, React Native, Firebase

\section{Mobile-Based Online Fish Auction (E-Auction) Application}

\begin{abstract}
Marketing of fish fishermen's catch in Indonesia, done by auctioning fish at the Fish Auction Place located in the Port. An auction is an open sale process between the seller and the bidder, which offers the highest price on any goods or services. Marketing with open auctions like this can be fraudulent, for example price manipulation from the auction party to fishermen. Such marketing can have an effect on the declining quality of fish, resulting in low selling prices. Based on the problem there is an e-auction app catchment fisherman based mobile apps, which can help fish marketing in small areas. E-auction is an auction process, which is done online or does not have to be where the auction takes place. This research uses Agile Software Development methods. As for the data source used, i.e., primary and secondary data. The app's development uses the React Native framework, Firebase as a back-end, and several tools that support application development. The result of this study is a mobile application, which can be installed on multiple Smartphone devices. The app can help efficiently marketing fish, and bidders can bid on any auction they want to participate in.
\end{abstract}

Keywords: E-Auction, Mobile Application, React Native, Firebase

\section{Pendahuluan}

Indonesia bagian Timur merupakan salah satu penghasil ikan terbesar di Indonesia. Ikan yang berasal dari Indonesia sering di ekspor ke beberapa negara, jenis ikan air asin merupakan ikan yang sering di ekspor. Pada saat ini Tempat Pelelangan Ikan yang berada di Pelabuhan atau Pangkalan Pendaratan ikan, menjadi sebuah pasar bagi para nelayan untuk memasarkan ikan hasil tangkapan mereka. Lelang sendiri merupakan suatu aktivitas jual beli barang maupun jasa, yang dalam prosesnya penjual menawarkan harga ke penawar atau calon pembeli, bagi penawar atau calon pembeli dengan tawaran harga lebih tinggi, maka penawar tersebut berhak atas barang atau jasa yang di tawarkan [1].

Pemasaran ikan yang terjadi saat ini adalah dengan cara pelelangan secara tradisional, dimana para pembeli harus dating ke Pelabuhan untuk melakukan penawaran harga terhadap ikan yang akan dibeli. Namun, masalah muncul seperti terjadi kecurangan dari pihak-pihak yang tidak bertanggung jawab. Selain itu, dengan cara manual dapat berdampak pada kualitas ikan, yang tidak akan segar lagi. 
Waktu yang menjadi penyebabnya dimana belum tentu setiap orang di perusahaan dapat mengangkat telepon dari para nelayan, sehingga menyebabkan para nelayan mengalami kerugian, karena kualitas yang ikan menurun.

Perkembangan teknologi saat ini begitu pesat. Penggunaan Smartphone merupakan contoh dari perkembangan teknologi, yang digunakan oleh berbagai kalangan orang untuk melakukan aktivitas online, seperti membuka media sosial, sarana belajar-mengajar, diskusi pekerjaan, e-banking, proses jual-beli, dan E-Auction [2]. E-auction merupakan aplikasi lelang yang dilakukan secara online, namun terpercaya secara keamanan. Penggunaan E-Auction dalam proses pelelangan lebih efektif, efisien dan transparan dibandingkan dengan cara tradisional, yang dimana bisa terjadi kecurangan dari pihak yang tidak bertanggung jawab [3]. Contoh kecurangan yang terjadi, yaitu manipulasi harga dari pihak pelelangan ke nelayan, dimana harga yang diberikan begitu rendah dari pada harga yang ditawarkan ke peserta lelang, saat proses lelang terjadi [4].

Dengan melihat permasalahan tersebut, maka peneliti akan membuat aplikasi E-lelang hasil tangkapan ikan nelayan berbasis mobile. Aplikasi ini dapat membantu pemasaran ikan secara efisien, dan penawar dapat melakukan bid pada setiap lelang yang ingin diikuti.

\section{LANDASAN TEORI}

\section{A. E-Lelang}

Elektronik-Lelang atau dikenal dengan e-auction merupakan terobosan baru bagi para pihak yang biasa melakukan proses pelelangan secara langsung atau manual. Proses dari e-lelang sendiri sebenarnya sama saja dengan proses lelang manual, yang membedakan para peserta lelang tidak perlu berada di tempat pelelangan, namun dengan pemanfaatan internet dan smartphone para peserta bisa melakukan proses lelang. Pada proses lelang secara online seperti ini prosedur dan konsepnya sama saja dengan proses lelang secara manual, dimana pelelang akan memberikan harga awal, namun pada e-lelang peserta lelang akan memasukkan jumlah bid yang dimana jumlah kelipatan bid berikutnya sudah diatur oleh pihak pelelang. Dalam proses lelang seperti ini juga diatur waktu pelaksanaannya sehingga peserta lelang dapat memasukkan bid dengan kelipatan tertinggi sampai batas waktu yang diberikan. Sistem akan mencatat semua aktivitas dari awal hingga berakhirnya proses lelang [4][5].

\section{B. React Native}

React Native merupakan sebuah Framework yang banyak digunakan untuk pembuatan aplikasi seluler. Berbeda dengan Framework pada umumnya yang menggunakan pemograman PHP [6], Framework ini menggunakan bahasa pemograman JavaScript [7], dimana dengan menggunakan Framework ini kita dapat membuat aplikasi seluler, yang dapat berjalan di dua sistem operasi sekaligus, yaitu pada Android dan iOS. React Native memudahkan para pengembang untuk membuat aplikasi dan UI yang nyata, dikarenakan React Native menyediakan kumpulan kode dalam Library yang dapat digunakan pengembang. React Native menggunakan Native Component dan Native API, yang membuat kode JavaScript Developer akan di-Bridging ke Native iOS dan Android. Kode yang sederhana merupakan sebuah keuntungan dalam menggunakan React Native, setiap bagian yang akan di tampilkan di screen itu dipisah menjadi Component. Method Return yang digunakan untuk menampilkan data ke screen, yaitu <View>. Pengembangan aplikasi seluler menggunakan React Native, bisa menggunakan pengembangan Expo Cli dan React Native Cli. Pengembangan Expo biasanya digunakan oleh para pengembang seluler pemula, dikarenakan tersedia fitur-fitur yang lebih mudah di pahami. Pengembagan React Native Cli biasanya digunakan oleh para pengembang seluler yang sudah terbiasa, dengan pengembangan seluler [8][9].

\section{Firebase}

Firebase merupakan sebuah layanan dari Google, dan bersifat Cloud Database. Firebase membantu para pengembang untuk mengembangkan aplikasi seluler dan web, yang membutuhkan realtime database. Firebase menyedikan berbagai fitur database dan API, agar pengembang dapat menyimpan dan mensinkronisasi data secara realtime, yang dapat dilakukan oleh setiap client yang terhubung. Firebase bersifat NoSQL database, dimana database ini memiliki konsep non-relasional. Konsep database NoSQl, sering digunakan untuk menyimpan dan mengambil data dengan skala besar. Penggunaan database NoSQL yang fleksibel dalam pembuatan aplikasi ini memabntu penggembang. Data pada database NoSQL akan tersimpan pada sebuah dokumen dalam format JSON, dimana dokumen tersebut dapat digunakan dengan menghubungkan API key dari firebase ke aplikasi yang dibuat [10][11].

\section{METODOLOGI}

Metode yang digunakan dalam penelitian ini adalah metode Agile. Agile Software Development merupakan sekumpulan metode pengembangan yang Iterative dan Incremental [12].

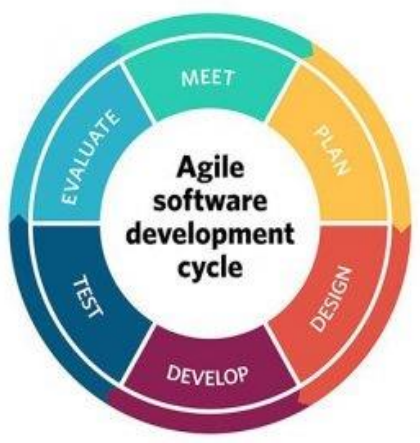

Gambar 1. Agile Software Development

Agile Software Development digunakan oleh developer dengan bentuk tim, agar dapat membuat dan menghasilkan sebuah software yang sesuai dengan permintaan User. Metode ini membantu para developer membuat software secara bertahap, sehingga menjadi lebih efektif dan efisien. 
Para developer dapat memberikan ide-ide baru ketika di tengah proses pembuatan software, terjadi sebuah ketidaksesuaian, oleh karena itu dapat langsung diperbaiki. Pekerjaan yang ada dalam metode ini dilakukan secara beraturan dan terjadwal, contohnya apa yang dilakukan hari ini, dan besok, sehingga developer bisa melakukan review pekerjaan kemarin apabila terjadi ketidaksesuaian. Metode ini membuat peneliti dapat melakukan perubahan pada saat proses pengembangan software, atau pun saat software sudah dirilis, untuk meningkatkan kinerja software, dan bisa menghasilkan software e-lelang yang sederhana bagi para nelayan sesuai dengan kebutuhan untuk memasarkan hasil tangkapan ikan. Metode ini memiliki tahapan pada umumnya, yaitu meet, plan, design, develop, test, dan evaluate.

1) Meet: Pada Tahap ini peneliti berkomunikasi dan bertemu secara langsung dengan User, yaitu nelayan agar mendapatkan informasi lebih lanjut mengenai pemasaran ikan.

2) Plan: Dengan informasi yang didapatkan, pengembang membuat perencanaan mengenai aplikasi yang akan dibuat dan apa saja fitur-fitur yang ada. Pada tahap ini dilakukan pembuatan wireframe dari aplikasi.

3) Design: Pada tahap ini dilakukan desain User Interface (UI) dari setiap halaman dari aplikasi yang akan dibuat dengan menggunakan aplikasi Figma.

4) Develop: Pada tahap ini dilakukan proses slicing dari desain UI yang sudah dibuat sebelumnya. Dalam proses slicing metode yang digunakan adalah metode Atomic Design [13]. Pada tahap ini juga dilakukan proses integrasi dengan Firebase.

5) Test: Tahap ini peneliti melakukan proses uji coba terhadap aplikasi yang sudah dibuat

\section{HASIL DAN PEMBAHASAN}

\section{Desain Aplikasi}

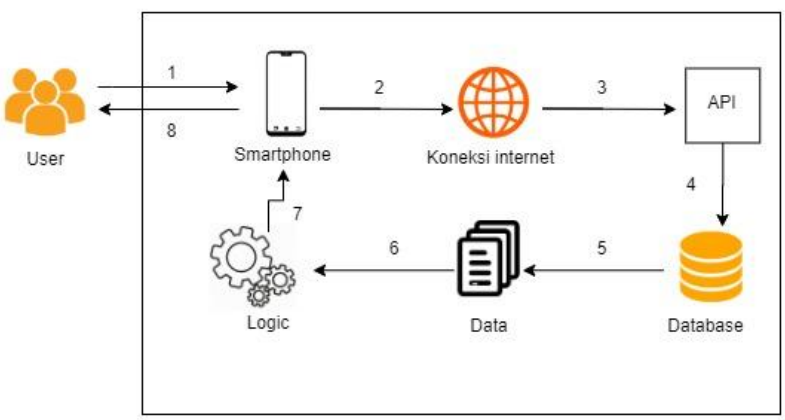

Gambar 2. Desain Aplikasi

Gambar 2 menampilkan langkah-langkah yang dilakukan oleh user dalam menggunakan aplikasi. User disini berperan sebagai pelelang dan penawar, dimana dapat menggunakan smartphone untuk menjalankan aplikasi. Smartphone digunakan untuk menajalankan aplikasi e-lelang yang sudah terinstall, dimana Smartphone harus terhubung dengan koneksi internet agar bisa mengakses data dari database. Koneksi internet sangat dibutuhkan untuk menjalankan aplikasi e-lelang ini, agar dapat melakukan proses lelang, mengakses dan menyimpan informasi di database. API digunakan untuk mengakses database, dimana peneliti menggunakan API key dari firebase untuk terhubung dengan aplikasi e-lelang. Database yang sudah terhubung dengan API akan membuat user menginput, menyimpan, dan mengakses informasi. Informasi dari database dikumpulkan menjadi sebuah data, dan kemudian diolah oleh logic agar dapat di tampilkan pada smartphone pengguna.

Peneliti menggunakan beberapa fitur firebase database, yaitu:

6) Firebase Authentication: Digunakan sebagai database yang menangani dan menyimpan data, seperti data Login, Logout, dan daftar dari pengguna aplikasi, yang dibuat oleh peneliti.

7) Firebase Realtime Database: merupakan kumpulan dari Database yang digunakan oleh pengembang pada aplikasi yang dibuat. Data pada setiap Client yang terhubung dengan Realtime Database ini, dapat secara langsung mengalami pembaharuan.

\section{E. Use-case Diagram}

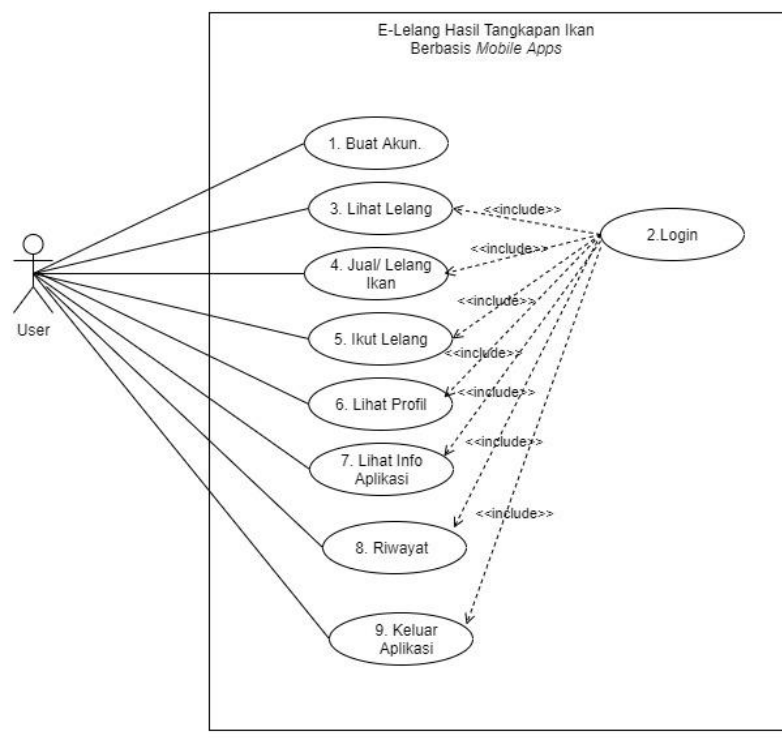

Gambar 3. Use-case Diagram

Pada Gambar 3 terlihat bahwa aplikasi ini memiliki 1 jenis pengguna yaitu user. User disini dapat berperan sebagai pelelang dan juga penawar. Untuk dapat mengakses menu-menu yang ada dalam aplikasi user harus login terlebih dahulu.

\section{F. Implementasi Tampilan Aplikasi}

8) Halaman Splash: Gambar 4 merupakan tampilan dari halaman Splash dimana halaman ini akan muncul pertama kali saat pengguna membuka aplikasi. 


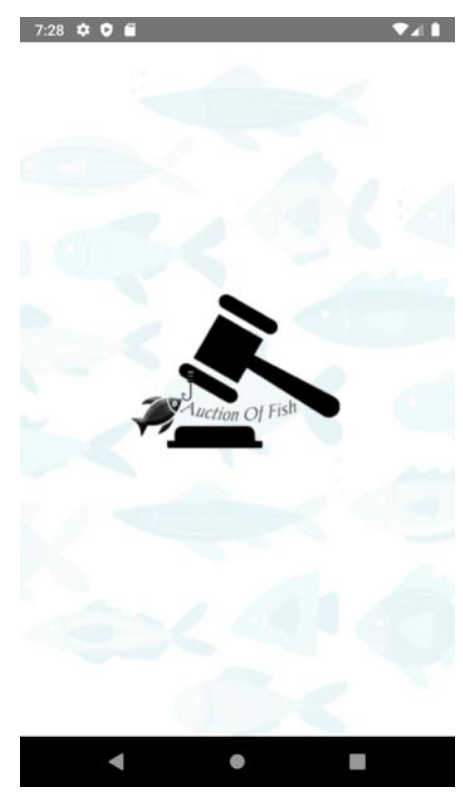

Gambar 4. Halaman Splash

9) Halaman Login: Pada Gambar 5 merupakan tampilan halaman login. Pada halaman ini pengguna yang sudah memiliki akun, dapat memasukkan email dan kata sandi pada bagian yang sudah disediakan, kemudian menekan button masuk. Pengguna akan di arahkan pada halaman beranda. Pengguna yang belum memiliki akun dapat menekan link daftar akun, untuk membuat akun terlebih dahulu.

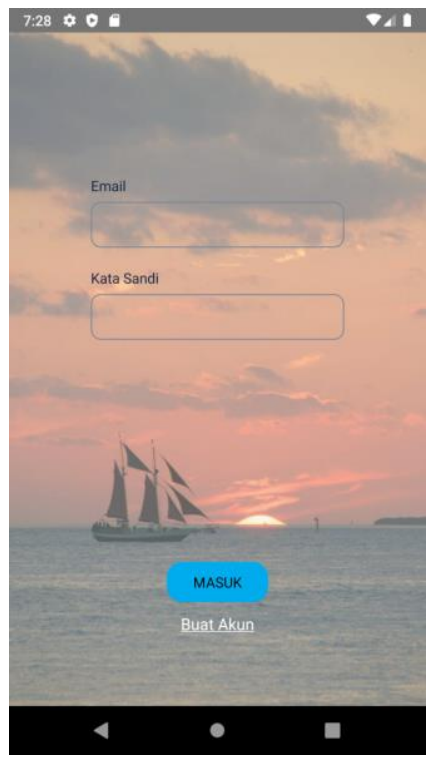

Gambar 5. Halaman Login

10) Halaman Registrasi: Pada Gambar 6 merupakan tampilan halaman registrasi. Pada tampilan halaman ini, pengguna dapat membuat akun dengan mengisi informasi akun pada bagian yang sudah disediakan.
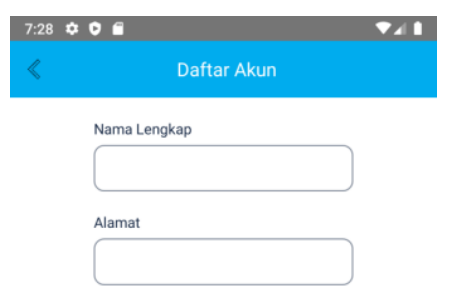

Nomor HP

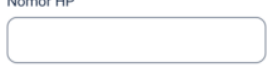

Email

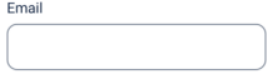

Kata Sandi
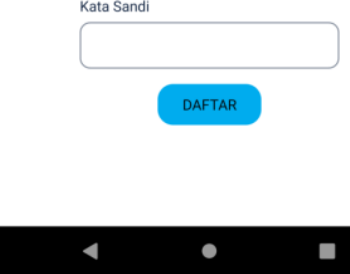

Gambar 6. Halaman Registrasi

11) Halaman Beranda: Pada Gambar 7 merupakan tampilan halaman beranda. Tampilan halaman ini terdapat daftar lelang yang di buka oleh penjual. Pada halaman ini pengguna dapat mengikuti lelang dengan menekan button bid. Bid yang dilakukan secara otomatis diatur oleh penggembang akan bertambah sebesar Rp. 50.000/bid. Pada setiap lelang terdapat kontak penjual yang memungkinkan penawar mendapatkan informasi lebih mengenai jenis ikan yang dilelang dengan menekan button pesan yang akan terhubung dengan aplikasi chatting WhatsApp. Pada halaman ini setiap pelelang dapat menghapus lelang sesuai jam berakhir, dengan menekan button hapus.
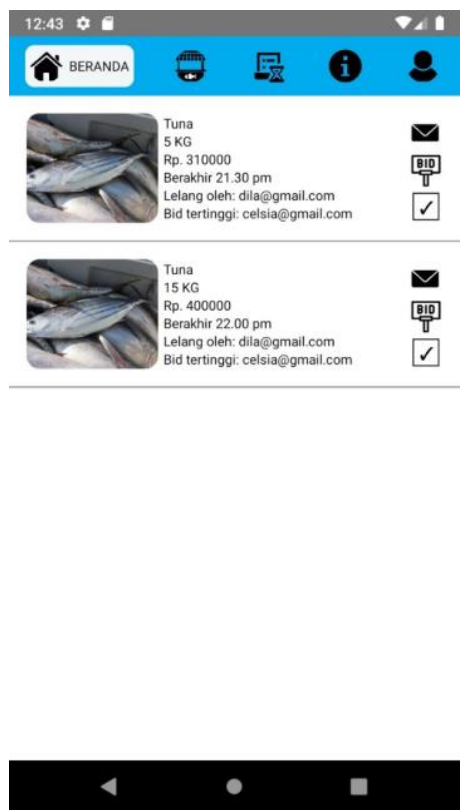

Gambar 7. Halaman Beranda

12) Halaman Jual/Lelang: Pada Gambar 8 merupakan tampilan halaman jual/lelang ikan. Tampilan halaman ini terdapat bagian deskripsi ikan yang akan dijual/dilelang 
oleh pengguna. Pengguna mengisi setiap bagian deskripsi ikan dan menekan button jual, agar ikan dapat di lelang pada halaman beranda.

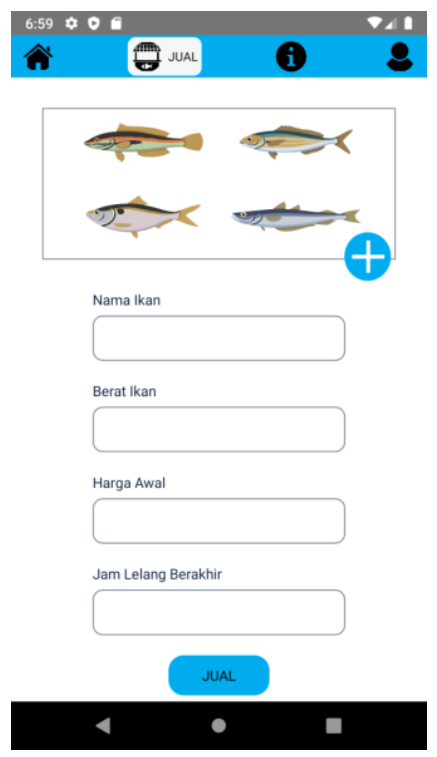

Gambar 8. Halaman Jual / Lelang

13) Halaman History: Pada Gambar 9 merupakan halaman riwayat. Tampilan ini berisikan daftar penawaran dari setiap pengguna, yang mengikuti lelang.
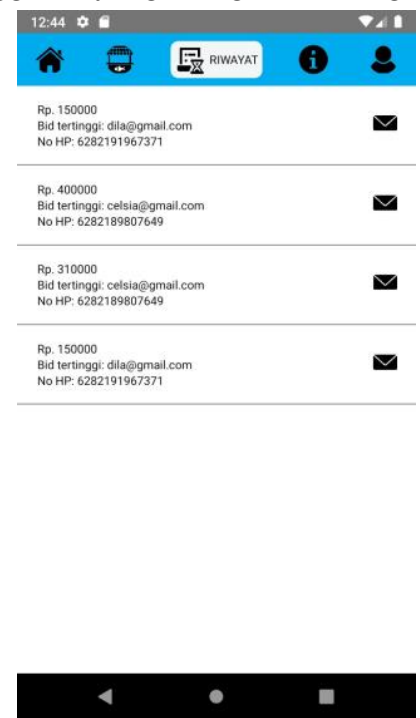

Gambar 9. Halaman History

\section{KESIMPULAN}

Berdasarkan hasil perancangan aplikasi E-Lelang untuk hasil tangkapan ikan nelayan berbasis mobile, maka dapat diambil beberapa kesimpulan yaitu, aplikasi ini dapat membantu pemasaran ikan dimana proses lelang dilakukan secara online atau tidak harus berada di tempat lelang berlangsung. Aplikasi ini juga dapat membuat proses pelelangan lebih efektif, efisien dan transparan dibandingkan dengan cara tradisional, yang dimana bisa terjadi kecurangan dari pihak yang tidak bertanggung jawab. Sebagai saran agar aplikasi ini dapat menjadi lebih baik adalah dengan menambahkan fitur push notification [14][15].

\section{DAFTAR PUSTAKA}

[1] G. Lavictory, B. A. Wibowo, dan B. B. Jayanto, "Analisis Tingkat Efisiensi Tempat Pelelangan Ikan (TPI) di Kabupaten Pemalang," J. of Fisheries Resources Utilization Management and Techno., vol. 5, no. 4, pp. 141 - 146, 2016.

[2] I. M. A. Artawan dan I. Paramitha, "Rancang Bangun Aplikasi Elektroni Koperasi Indonesia (E-Koin) Berbasis Mobile," Jurnal Ilmiah Teknik Informatika dan Sistem Informasi, vol. 9, no. 1, pp. $85-94,2020$

[3] C. Zhou, C.-K. Tham dan M. Motani, "Online auction for scheduling concurrent delay tolerant tasks in crowdsourcing systems," Computer Networks, vol. 169, 2020.

[4] A. Setiawan, R. Soelaiman, dan R. J. Akbar, "Rancang Bangun Aplikasi Pelelangan Online (E-Auction) Berbasis Perangkat Bergerak Android,” Jurnal Teknik ITS, vol. 6, no. 2, pp. 532 - 536, 2017.

[5] J. Zhang, N. Xie, X. Zhang, dan W. Li, "An online auction mechanism for cloud computing resource allocation and pricing based on user evaluation and cost," Future Generation Computer Systems, vol. 89, pp. 286-299, 2018.

[6] S. Andolo and S. I. Adam, "A New PHP Web Application Development Framework Based on MVC Architectural Pattern and Ajax Technology," in 2019 1st International Conference on Cybernetics and Intelligent System (ICORIS), Bali, 2019.

[7] F. Kereki and R. O. Ramos, Modern JavaScript Web Development Cookbook: Easy solutions to common and everyday JavaScript development problems, Birmingham: Packt Publishing Limited, 2018.

[8] B. Eisenman, Learning React Native: Building Native Mobile Apps with JavaScript, USA: O’Reilly Media, 2016

[9] P. D. A. Wiguna, I. P. A. Swastika and I. P. Satwika, "Rancang Bangun Aplikasi Point of Sales Distro Management System dengan Menggunakan Framework React Native," Jurnal Nasional Teknologi dan Sistem Informasi, vol. 4, no. 3, pp. 150-159, 2018.

[10] A. Sonita dan R. F. Fardianitama, "Aplikasi E-Order Menggunakan Firebase dan Algoritma Knuth Morris Pratt Berbasis Android, “ Jurnal Pseudocode, vol. 5, no. 2, pp. 38 - 45, 2018.

[11] M. Ilhami, "Pengenalan Google Firebase Untuk Hybrid Mobile Apps," Jurnal IT CIDA, vol. 3, no. 1, pp. 16 - 29, 2017.

[12] Pressman, R. S, Software Engineering: A Practitioner's Approach, London: Palgrave Macmilan, 2015.

[13] B. Frost, "Atomic Design Methodology," [Online]. Available: http://atomicdesign.bradfrost.com/chapter-2.

[14] M. Irsan, "Rancang Bangun Aplikasi Mobile Notifikasi Berbasis Android Untuk Mendukung Kinerja Di Instansi Pemerintah," Sistem dan Teknologi Informasi, vol. 3, no. 1, pp. 6, 2015

[15] R. Somya dan M. Aprillia, "Perancangan Aplikasi Push Notification Center dengan Teknologi Firebase Cloud Messaging di PT. Sumber Trijaya Lestari," Jurnal SIMETRIS, vol. 10, no. 1, pp. $211-222,2019$. 